\title{
Formulation, Quality and Antimicrobial Activity of Ointments and Soaps Based on the Bark Extracts of Ziziphus mauritiana and Ziziphus mucronata
}

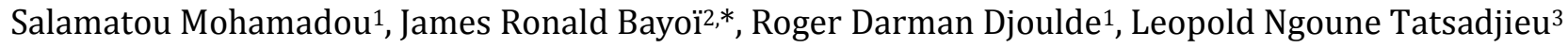

${ }^{1}$ Department of Agriculture, Livestock and Postharvest Technology, National Advanced School of Engineering Maroua, P.O Box 46, Maroua, Cameroon. 2Department of Biological Sciences, Faculty of Science, University of Maroua, P.O. Box 814, Maroua, Cameroon.

${ }^{3}$ Department of Food Engineering and Quality Control, University Institute of Technology, P.0. Box 454, Ngaoundere, Cameroon.

\section{ARTICLE DETAILS}

\section{Article history:}

Received 12 December 2021

Accepted 30 December 2021

Available online 01 February 2022

\section{Keywords:}

Galenic Formulation

Ointment

Soap

Ziziphus Bark Extracts

Bioactive

\section{A B S T R A C T}

This study aimed to evaluate the quality and antimicrobial activity of soaps and ointments enriched with aqueous ethanol extracts from barks of Ziziphus mauritiana and Ziziphus mucronata. The galenic formulation allowed the development of ointments as well as soap based on aqueous ethanol extract $(70 \%, v / v)$ using some excipients. The consistency of the ointments was slightly hard but softens immediately on contact with the skin. The preparation method allowed to get a very good homogeneity with a regular distribution of the extracts. The ointments were stable and no changes on the surface was observed. The ointments were found slight acidic, with $\mathrm{pH}$ values varying from 5 to 5.59 . It was noticed that enriched soaps displayed neutral $\mathrm{pH}$ values neutral varying from 7.28 to 7.49. Moreover, the soap enriched with Z. mauritiana (84\%) was more foaming in saline environment than that enriched with $Z$. mucronata (61.53\%). Both bark extract-enriched ointments and soaps displayed excellent antimicrobial activity against fungi and bacteria found on the skin and hands.

\section{Introduction}

Dandruff (hair, nails) and skin have a protective function against external aggression. These parts of the human body are also subject to diseases which can be grouped into two main groups: bacterial and fungal infections. For the bacterial skin infections, Staphylococcus spp infinitely dominates. Staphylococcus aureus is a Gram-positive bacterium that is of utmost importance in infectious skin pathology [1]. The most common infections are skin and soft tissue infections including: folliculitis, boil, anthrax, abscess, cellulitis, impetigo, post-operative surgical wound infections and osteomyelitis [2]. As for cutaneous mycoses, they are due to fungi: yeasts, dermatophytes. Superficial yeast infections are mostly candidiasis ( $80 \%$ of cases), they are caused by species of the genus Candida. The infections are: Candida intertrigo, Candida perionyxis and onyxis and chronic mucocutaneous candidiasis [3]. To treat these infections, antibiotics and antifungals are used. Since the 1940s, antimicrobials (antibiotics, antivirals, antifungals and antiparasitics) have greatly reduced mortality from infectious diseases. Unfortunately, these products are not available to everyone, and many people continue to face the scarcity of drugs in the public sector, forcing them to turn to the private sector, where prices can be substantially higher. In the private sector, the price for cheaper generics drugs was on average five times higher than their international reference price and as high as about 16 times that price in some countries [4].

Plants are natural reservoir of antimicrobial agents of medicinal values. These agents are thought to be almost free from the side effects usually associated with synthetic antimicrobials. So many of the present day drugs are known to have been isolated from natural sources and their isolations were based on the information about the uses of the agents in folklore medicine [5]. So-for many millions of people, herbal medicines, and traditional treatments and traditional practitioners are the main or even the only source of health care $[5,6]$. In a context of growing poverty, nonaccessibility to imported therapeutics and to derive real benefit from the use of medicinal plants, it becomes imperative to initiate scientific research work for the rational exploitation of the indisputable virtues of the plants of our pharmacopoeia to achieve the production of new plant- based products that would be effective against fungal and bacterial infections, at lower cost and accessible to all. It is in this concern that we have undertaken a study on two local plants (Ziziphus mauritiana and Ziziphus mucronata) to produce soaps and ointments enriched with aqueous ethanol extracts (of bark) of these plants. Ziziphus is a genus of about 100 species of spiny shrubs and small trees in the buckthorn family, Rhamnaceae, distributed in the warm-temperate and subtropical regions throughout the world [5]. The best known species is Z. ziziphus (Jujube). In Cameroon, 4 species have been identified Ziziphus mauritiana, Ziziphus spina-christi, Ziziphus abyssinica and Ziziphus mucronata. Z. mauritiana or jujube of tropical Africa is widely known either as a spontaneous or naturalized shrub, or as a cultivated fruit tree that has become subspontaneous in some places. This species is undoubtedly native to Africa and covers the most extensive area of the globe surface of all species of the genus Ziziphus. Ziziphus mucronata Willd. subsp. mucronata Willd., also known as buffalo thorn, is a small to medium-sized tree, with a spreading canopy. It is distributed throughout the summer rainfall areas of sub-Saharan Africa, extending from South Africa northwards to Ethiopia and Arabia. Its bark and roots are used medicinally for the treatment of various ailments, including rheumatism, gastrointestinal complaints and snake bites [6]. Warm bark infusions are used for body pains, expectorants in cough, respiratory infections and chest problems. Ziziphus have very nutritious fruits and are usually eaten fresh. The fruits are applied on cuts and ulcers. They are also used to treat pulmonary ailments and fevers and to promote the healing of fresh wounds, for dysentery. The leaves are applied as poultices and are helpful in liver troubles, asthma and fever [7]. Many studies have reported antimicrobial activity of Ziziphus sp. extracts $[8,9]$. The methanolic extract has activity on Escherichia coli, Bacillus subtilis, Staphylococcus aureus, Aspergillus niger, Fusarium solani [10]. A recent study revealed significant results of antimicrobial activity of aqueous ethanol $(70 \%, \mathrm{v} / \mathrm{v})$ extracts of bark and leaf from $Z$. mauritiana and $Z$. mucronata $[11,12]$.

The current study aims to evaluate the quality and biological activity of ointment and soap enriched with aqueous ethanol extract from barks of Ziziphus mauritiana and Ziziphus mucronata, in accordance with the logic of contributing to the search for new alternatives to alleviate the cost problems of commercially available antimicrobials while enhancing traditional medicine. 


\section{Experimental Methods}

\subsection{Plant Materials}

The barks of Ziziphus mauritiana and Ziziphus mucronata were collected in January 2020 in localities of Mokolo (Mayo-Tsanaga Department) and Kaele (Mayo-Kani Department), respectively. The identification of plant material was carried out by experts from IRAD centre of Maroua. The barks were chosen because they are the most used parts in traditional pharmacopoeia and our previous study showed that they exerted a very good in vitro antimicrobial activity against both bacteria and fungi [11].

\subsection{Biological Materials}

The microbial strains consisted of 4 fungi namely Candida albicans, Fusarium monoliforme, Rhodotorula mucillaginosa and Aspergillus flavus and two bacteria: Staphylococcus aureus and P. aeruginosa (Table 1).

Table 1 List of microorganisms procured from Food Microbiology laboratory ENSAI, Ngaoundere University, Cameroon

Names of microorganisms

Pseudomonas aeruginosa

Staphylococcus aureus

Fusarium monoliforme

Rhodotorula mucillaginosa

Aspergillus flavus

Candida albicans

References
UBOCC-A-316004
UBOCC-A-316003
UBOCC-A-101149
UBOCC-A-214112
UBOCC-A-111076
UBOCC-A-211002

2.3 Preparation of Bark Extracts from Ziziphus mauritiana and Ziziphus mucronata

The bark extracts from these plants were prepared according to the previously described method [11]. One hundred gram of bark powder were macerated in Erlenmeyer containing $400 \mathrm{~mL}$ of aqueous ethanol solution $(70 \%, \mathrm{v} / \mathrm{v})$. The mixture was stirred for $4 \mathrm{~h}$ and allowed to stand for $24 \mathrm{~h}$. After that, it was filtered through Whattman No.1 filter paper. This operation was repeated trice and the filtrates were concentrated up to dryness using a rotavapor. The extracts were collected in sterilised bottles, sealed and the yield was calculated using the formula below.

$$
\text { Yield }(\%)=\frac{m E}{m V} \times 100
$$

where, $\mathrm{mE}$ represents the mass of the extract, and $\mathrm{mV}$ is the mass of the plant material.

\subsection{Ointment Formulation}

The modified method to that described by Bene et al. [13] was used. Extracts (bark extracts) with the highest antimicrobial activity were used for the galenic formulation of the ointments and soaps. The ointments were prepared using natural products (Fig. 1). The shea butter and honey were weighed and melted in a warm water bath. The molten semi fluid was mixed in a porcelain crucible, warmed and the bark extract of Ziziphus mauritiana or Ziziphus mucronata as active ingredient were added. The whole mixture was stirred and allowed to cool before adding Vitamin E. The mixture was again stirred and poured in an airtight container and stored at room temperature at the end three ointments were prepared; two enriched with the bark extract of Ziziphus mauritiana or Ziziphus mucronata and a non-enriched ointment used as control (Fig. 2).

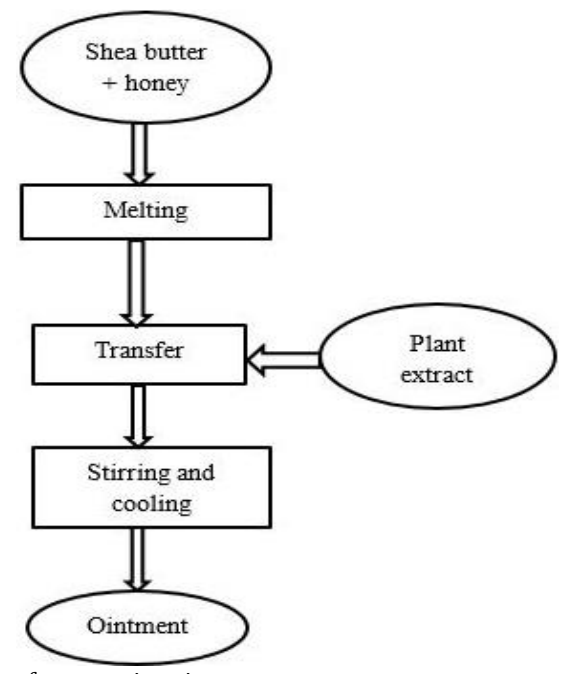

Fig. 1 Flowchart for preparing ointment https://doi.org/10.30799/jpmr.058.22010101

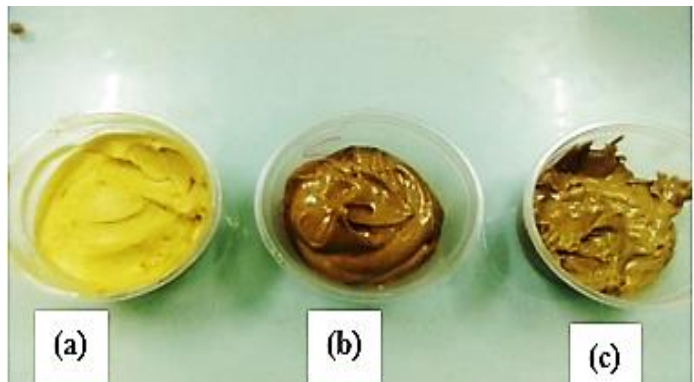

Fig. 2 (a) Neutral ointment; (b) Enriched ointment with bark extract of Ziziphus mauritiana; and (c) Enriched ointment with bark extract of Ziziphus mucronata extract

\subsection{Soap Formulation}

The hot saponification method of liquid soap production was used as described by Sellah and Mokri [14]. Hot saponification was chosen because of the ease of the method, it does not require much energy, a lot of equipment and there is no wastewater discharge. To obtain a soap of good quality (colour, non-irritating, quick and stable foaming), an oil mixture (palm kernel oil, bleached palm oil and groundnut oil) was used (Fig. 3). The elementary constituents of soap preparation were weighed. Caustic soda was gently dissolved in distilled water in a glass vessel (not the reverse), stirred to achieve a complete dissolution and the solution was maintained between $40{ }^{\circ} \mathrm{C}$ and $45^{\circ} \mathrm{C}$. Like, the caustic soda, the oils were melted, warmed and maintained at $44^{\circ} \mathrm{C}$ and $45^{\circ} \mathrm{C}$ in a water bath The two suspensions of the same temperature were simultaneously mixed in a plastic container (soda solution was poured onto the oil) upon continuous stirring to obtain a homogeneous mixture. The traceless mixture was cooked over the water bath to obtain a paste with a translucent appearance (Fig. 4a). The paste was allowed to cool before adding the active ingredient, bark extract of Ziziphus mauritiana or Ziziphus mucronata (Fig. 4a). The liquid soaps were prepared by diluting the paste soaps. For this, sterile distilled water (85\%) was added to the soap $(15 \%)$. The mixture was left to stand and mixed gently to avoid foaming until the soap paste was completely dissolved (Fig. 4b).

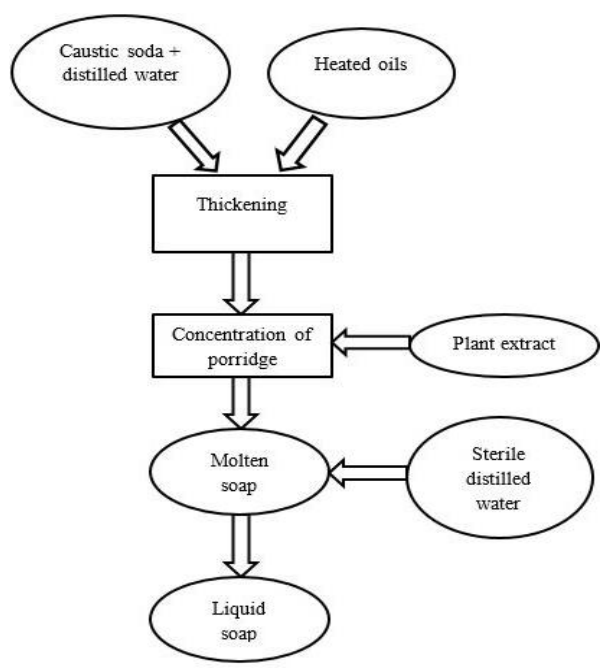

Fig. 3 Flowchart of soap production

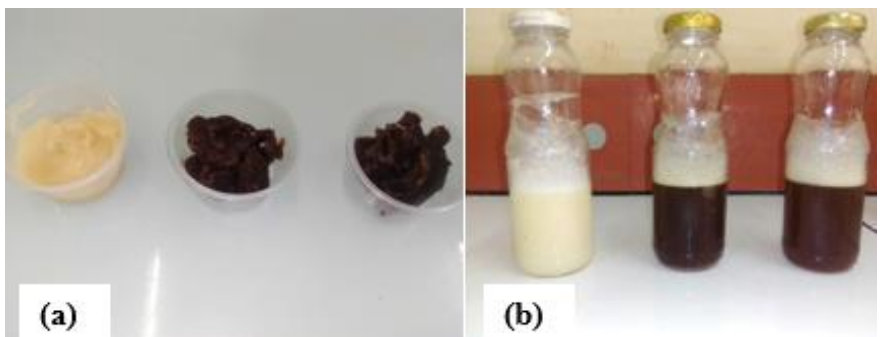

Fig. 4 (a) Paste soaps; (b) Liquid soaps (In each picture from left to right; neutral soap, soaps enriched with the bark extract of Ziziphus mauritiana and Ziziphus mucronata)

\subsection{Quality Control of Ointments}

The colour, odour, consistency, stability, $\mathrm{pH}$ and homogeneity were assessed according to the method described by Bene et al. [13]. Briefly, the $\mathrm{pH}$ was read directly from $10 \mathrm{~g}$ of melted ointment meanwhile the 
homogeneity was determined after spreading the ointment out in a thin layer on a flat surface using a spatula. As for the stability, it consisted initially in studying the melting temperature of the ointment and the evolution in time. Four batches will be left at rest at laboratory temperature and examined: permanently open batch, open batch and tested at each control, closed batch that will be opened at each control, permanently closed batch until the end of the experiment.

\subsection{Quality Control of Soaps}

Using the previously described methods, the $\mathrm{pH}$ and foaming power were determined [14,15]. Summarily, $0.5 \mathrm{~g}$ of soap and $150 \mathrm{~mL}$ of distilled water were mixed, stirred continuously for 2 minutes likewise the foaming power of soap was determined in various media (acidic, saline and aqueous (distilled water)). The acidic medium was prepared by adding 1 $\mathrm{mL}$ of hydrochloride acid solution ( $1 \mathrm{mmol} / \mathrm{L})$ to $2 \mathrm{~mL}$ of the soap solution in a test tube. As for the saline medium, $1 \mathrm{~mL}$ of a saline solution of $\mathrm{NaCl}$ (30\%) was added to $2 \mathrm{~mL}$ of the soap solution. Similarly, $3 \mathrm{~g}$ of soap was dissolved in $100 \mathrm{~mL}$ of distilled water to serve as control. The tubes were corked and shaken in a horizontal position for about 15 seconds and after 5 minutes, the height of the foam was measured. The results were calculated and expressed as foaming rate using the formula below.

$$
\text { Foaming rate }(\%)=\frac{\text { Foam height of sample }}{\text { Foam height of control }} \times 100
$$

\subsection{Product Efficiency}

\subsubsection{Antimicrobial Testing of Ointments}

The antimicrobial screening test using the agar well method described by Méité et al. [16] was used. Bacterial (S. aureus, P. aeruginosa) and fungal (C. albicans, R. mucillaginosa, F. monoliforme, A. flavus) suspensions (50 $\mu \mathrm{L}$ ) were surface plated in $5 \mathrm{~cm}$ diameter Petri dishes containing the agar plates previously poured and left to cool at room temperature. Wells were made in the agar at a rate of one well per plate. These were impregnated with the different ointments previously melted at $37^{\circ} \mathrm{C}$ in a water bath. After incubating, the results were read by measuring the inhibition diameter in $\mathrm{mm}$, which corresponded to the antimicrobial activity of the ointments.

\subsubsection{Antimicrobial Assay of Soap Samples}

In line with the method described by Bennama [15], the operator's hands (volunteers) should not have been washed with an antiseptic or disinfectant product during the week preceding the experiments. The operator's hands should not have had any lesions, jewellery or nail polish on them during the study. To determine the antimicrobial activity of the soaps, different samples were collected before and after the hand washing. Firstly, the unwashed distal tips of the phalanges of fingers 2, 3 and 4 (index, middle and ring fingers) of each hand were pressed lightly for 5 seconds on the agar plates (one plate for the left hand and one for the right hand for each operator) to serve as control. Secondly, samples were collected after hand washing with the soap and running tap water at intervals after one minute, half an hour, one hour, two hours and four hours as in from the aforementioned phalanges.

The bacterial reduction rate was calculated to know the efficiency of the soaps using the following formula:

$$
\text { Reduction rate }(\%)=\frac{\text { Number of colonies after hand washing }}{\text { Number of colonies before hand washing }} \times 100
$$

\section{Results and Discussion}

\subsection{Quality and Effectiveness of Ointments and Soaps 3.1.1 Quality of Ointment}

The quality of the extract-enriched and neutral ointments are presented in Fig. 2. The neutral ointment was yellow in colour while the ointments with extracts were brown. The consistency of the ointments was solid and a slightly thick but softened immediately on contact with the skin. In addition, the ointments were homogenous with a regularly very good distribution of the extract. Irrespective of the stability test, all the ointments were stable with no observable changes at the surface of the ointments were exposed. The addition of vitamin E may explain this stability, because vitamin E prevents the oxidation of fats. However, these results were different from those obtained by Yapi et al. [17]. These authors observed a slight change with the ointment enriched with aqueous ethanol extract of Aspilia africana (Pers.) C.D. Adams var. africana after one month in the permanently open batch. Likewise, the similar observations were made by Bene et al. [13] using antibacterial ointment based on a $70 \%$ aqueous ethanol extract of Bersama abyssinica stem bark. https://doi.org/10.30799/jpmr.058.22010101
The $\mathrm{pH}$ values of the ointments are shown in Table 2 . The $\mathrm{pH}$ nonsignificantly varied from 5 to 5.59 . The fact that the $\mathrm{pH}$ is acidic is a good indication, because the $\mathrm{pH}$ of the skin is acidic. So, the ointments will respect the $\mathrm{pH}$ of the skin and hence the balance of the skin will not be disturbed. Our results were similar to the findings of Bene et al. [13], who obtained a pH value of 5 with an antibacterial ointment based on a $70 \%$ aqueous ethanol extract of Bersama abyssinica stem bark using shea butter as an excipient.

Table $2 \mathrm{pH}$ values of ointments during storage at room temperature for a month

\begin{tabular}{llll}
\hline Days & $\begin{array}{l}\text { Neutral } \\
\text { ointment }\end{array}$ & $\begin{array}{l}\text { Z. mauritiana enriched } \\
\text { ointment }\end{array}$ & $\begin{array}{l}\text { Z. mucronata enriched } \\
\text { ointment }\end{array}$ \\
\hline 0 & $5.10 \pm 1.62^{\mathrm{A}, \mathrm{a}}$ & $5.16 \pm 1.13^{\mathrm{A} . \mathrm{a}}$ & $5.00 \pm 1.177^{\mathrm{A}, \mathrm{a}}$ \\
14 & $5.41 \pm 0.33^{\mathrm{A}, \mathrm{a}}$ & $5.21 \pm 0.34^{\mathrm{A}, \mathrm{a}}$ & $5.08 \pm 0.49^{\mathrm{A}, \mathrm{a}}$ \\
28 & $5.54 \pm 0.33^{\mathrm{A}, \mathrm{a}}$ & $5.31 \pm 0.32^{\mathrm{A}, \mathrm{a}}$ & $5.59 \pm 0.26^{\mathrm{A}, \mathrm{a}}$ \\
\hline
\end{tabular}

Z. mauritiana: Ziziphus mauritiana: Z. mucronata: Ziziphus mucronata. For each column, the values assigned to the same superscript capital letter are not significantly different $(p=0.05)$. For each row, the values assigned to the same superscript lowercase letter are not significantly different $(p>0.05)$

\subsubsection{Quality of Soaps}

Table 3 summarises the $\mathrm{pH}$ values of the soap samples. Irrespective of the samples, changes in $\mathrm{pH}$ during the storage was not significant $(\mathrm{p}>$ 0.05). The $\mathrm{pH}$ values of the soaps were neutral during the storage time. For the neutral soap, the initial pH was 7.34 (zeroth day) and after 28 days of storage at room temperature, it went to 7.74 . In the same line, the $\mathrm{pH}$ of enriched soaps went from 7.28 (day 0) to 7.49 on the $28^{\text {th }}$ day and from 7.31 (zeroth day) to 7.36 at the end for samples enriched with Ziziphus mauritiana and Ziziphus mucronata bark extracts, respectively. Despite these insignificant changes in $\mathrm{pH}$ of soap samples, these results did not agree with those obtained by Sellah and Mokri, and Bennama [14, 15] who recorded $\mathrm{pH}$ ranged between 9.35 to 9.91 and 10.5, respectively, with pasty and liquid soaps based on vegetable oils. The neutral $\mathrm{pH}$ of the soap samples can be explained by the addition of citric acid because it has the capacity to play an acidifying role.

Table $3 \mathrm{pH}$ values of soaps during storage at room temperature for a month

\begin{tabular}{llll}
\hline Days & Neutral soap & $\begin{array}{l}\text { Z. mauritiana } \\
\text { enriched soap }\end{array}$ & $\begin{array}{l}\text { Z. mucronata } \\
\text { enriched soap }\end{array}$ \\
\hline 0 & $7.34 \pm 0.28^{\mathrm{A}, \mathrm{a}}$ & $7.28 \pm 0.07^{\mathrm{A}, \mathrm{a}}$ & $7.31 \pm 0.16^{\mathrm{A}, \mathrm{a}}$ \\
14 & $7.71 \pm 0.41^{\mathrm{A}, \mathrm{a}}$ & $7.32 \pm 0.19 \mathrm{~A}, \mathrm{a}$ & $7.34 \pm 0.10^{\mathrm{A}, \mathrm{a}}$ \\
28 & $7.74 \pm 0.06^{\mathrm{A}, \mathrm{a}}$ & $7.49 \pm 0.17^{\mathrm{A}, \mathrm{a}}$ & $7.36 \pm 0.25^{\mathrm{A}, \mathrm{a}}$ \\
\hline
\end{tabular}

Z. mauritiana: Ziziphus mauritiana: Z. mucronata: Ziziphus mucronata. For each column, the values assigned to the same superscript capital letter are not significantly different $(p>0.05)$. For each row, the values assigned to the same superscript lowercase letter are not significantly different $(p>0.05)$

Table 4 presents the foaming rate of extract-enriched soaps in different environment. The addition of acid to the soap solutions leads to the formation of a precipitate and there was no foam formation compared to the control. The foaming rate was therefore equal to $0 \%$ for control and enriched soap samples in acidic environment. In saline environment, the extract-enriched soaps foamed but the quantity of foam was lower than that of the non-enriched control soap. For the neutral soap, the foaming rate was $90 \%$, while the soap samples enriched with Ziziphus mauritiana and Ziziphus mucronata bark extracts had foaming rate of $84.61 \%$ and $61.53 \%$, respectively. As shown in Fig. 5, the foaming rate of the soap with Ziziphus mucronata extract was the lowest compared to the other soap samples.

Table 4 Foaming rate of extracts enriched soaps in different environments

\begin{tabular}{llll}
\hline Environment & $\begin{array}{l}\text { Neutral } \\
\text { soap }\end{array}$ & $\begin{array}{l}\text { Z. mauritiana extract- } \\
\text { enriched soap }\end{array}$ & $\begin{array}{l}\text { Z. mucronata extract- } \\
\text { enriched soap }\end{array}$ \\
\hline Acidic & $0 \%$ & $0 \%$ & $0 \%$ \\
Saline & $90 \%$ & $84.61 \%$ & $61.53 \%$ \\
\hline
\end{tabular}

Z. mauritiana: Ziziphus mauritiana: Z. mucronata: Ziziphus mucronata
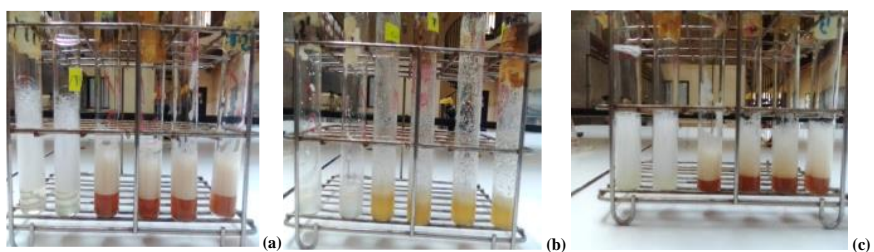

Fig. 5 Foaming rate of the different soaps (a) Neutral control medium (b) Acid medium and (c) Saline medium. In each picture, the first, second and third couple of tubes contained non-enriched control soap, Ziziphus mauritiana and Ziziphus mucronata extract-enriched soaps, respectively 
The results were consistent with those obtained by Bennama [15] with soap enriched to the essential oil of lemon (Citrus limon). However, the foaming rate in saline medium obtained by Bennama [15] was lower than the results obtained with our different soap samples. This difference can be explained by the oils used to enrich the soaps. Indeed, Bennama [15] only used olive oil during his study, while we incorporated a mixture of oils (peanut oil, palm kernel oil, bleached palm oil), to optimize the sensory properties in terms of colour, smell, no irritation and foaming capacity.

\subsection{Product Efficiency}

\subsubsection{Effectiveness of Ointments}

The antimicrobial screening assay of the ointments are presented in Table 5. The results show that the ointments have variable activities with inhibition diameter values ranging from $13.66 \pm 6.35 \mathrm{~mm}$ with Ziziphus mucronata bark extract ointment on Candida albicans to $10.33 \pm 0.75 \mathrm{~mm}$ with Ziziphus mucronata bark extract ointment on Fusarium moniliforme. Moreover, ointments enriched with Ziziphus mucronata bark extracts have only shown antifungal activity and they were no effective on bacterial species like Staphylococcus aureus and Pseudomonas aeruginosa. The bark extract of Ziziphus mucronata mixed to ointment has a strong activity on Candida albicans $(13.66 \pm 6.35 \mathrm{~mm})$ and Rhodotorula mucilaginosa $(12.00$ $\pm 2.64 \mathrm{~mm}$ ) and a medium activity on Aspergillus flavus (11.33 $\pm 1.52 \mathrm{~mm})$ and Fusarium moniliforme $(10.33 \pm 0.57 \mathrm{~mm})$. However, ointment blended with bark extract from $Z$. mauritiana recorded strong antimicrobial activity against Staphylococcus aureus (12.66 $\pm 2.51 \mathrm{~mm})$ and Pseudomonas aeruginosa $(12.00 \pm 2.00 \mathrm{~mm})$. No activity has been recorded with neutral ointment.

Table 5 Antimicrobial activity of Ziziphus bark extract-enriched ointments (Inhibition diameter in $\mathrm{mm}$ )

\begin{tabular}{llll}
\hline Microorganisms & $\begin{array}{l}\text { Control (non } \\
\text { enriched) }\end{array}$ & Z. mauritiana & Z. mucronata \\
\hline Staphylococcus aureus & No activity & $12.66 \pm 2.51^{\mathrm{A}}$ & No activity \\
Pseudomonas aeruginosa & No activity & $12.00 \pm 2.00^{\mathrm{A}}$ & No activity \\
Candida albicans & No activity & No activity & $13.66 \pm 6.35^{\mathrm{A}}$ \\
Rhodotorula mucilaginosa & No activity & No activity & $12.00 \pm 2.64 \mathrm{~A}$ \\
Fusarium moniliforme & No activity & No activity & $10.33 \pm 0.57^{\mathrm{A}}$ \\
Aspergillus flavus & No activity & No activity & $11.33 \pm 1.52^{\mathrm{A}}$ \\
\hline
\end{tabular}

Z mauritiana: Ziziphus mauritiana; $Z$ mucronata: Ziziphus mucronata For each column, the values assigned to the same superscript capital letter are not significantly different $(p<0.05)$. For each row, the values assigned to the same superscript lowercase letter are not significantly different $(p<0.05)$

\subsubsection{Effectiveness and Persistence Soaps}

The antibacterial efficacy and persistence of the soaps obtained are summarised in Figs. 6-8. The reduction rates of the different soaps varied significantly $(p=0.05)$. The lowest value of the reduction rate was $32 \%$ with the neutral soap at the fourth hour after washing (right hand) and the highest value, $100 \%$, was obtained with the extract-enriched soaps during one minute after hand washing. The reduction rates of the different extract-enriched soaps with extracts were higher than those of the neutral soap. The antibacterial efficacy decreased with time independently of the nature of soap. However, decrease was not significant with enriched soaps. For the neutral soap, the initial rates were $98.40 \%$ (left hand) and $98.38 \%$ (right hand) after a minute of action, while at the end, after 4 hours of action, they were $32.25 \%$ (left hand) and $32 \%$ (right hand). For the soap based on Ziziphus mauritiana bark extract, the initial rates after a minute of action were $100 \%$ (left hand and right hand). After 4 hours of action, they displayed reduction rate of $95.50 \%$ (left hand) and $87.69 \%$ (right hand). For soap with bark extract of Ziziphus mucronata, the initial rates (after a minute) were 100\% (left hand and right hand) at the end (4 hours of action), they were $97.11 \%$ (left hand) and $91.33 \%$ (right hand).

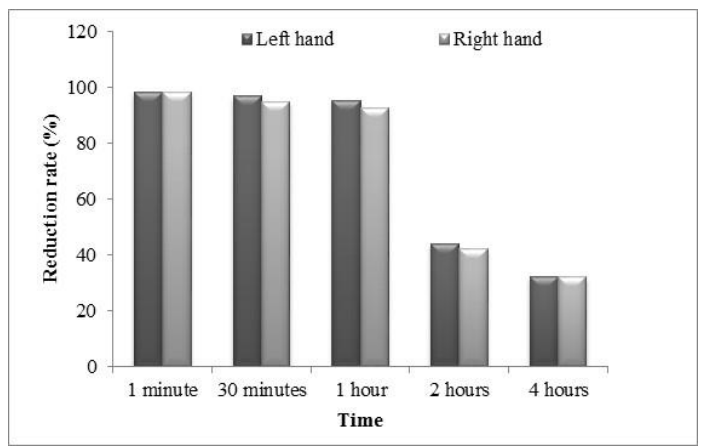

Fig. 6 Antibacterial efficacy of non-enriched soap https://doi.org/10.30799/jpmr.058.22010101

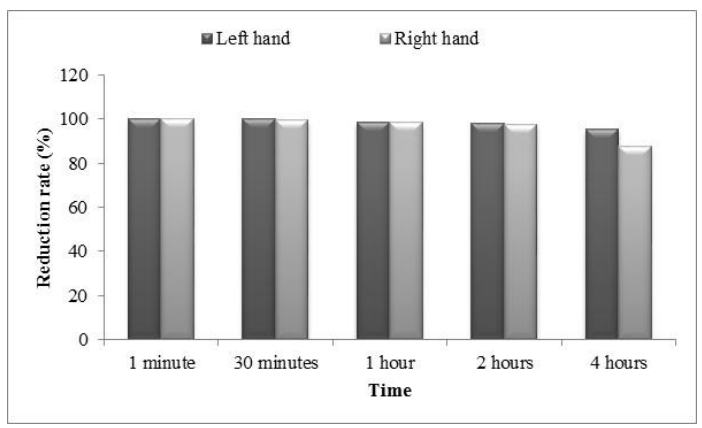

Fig. 7 Antibacterial efficacy of Ziziphus mauritiana bark extract soap

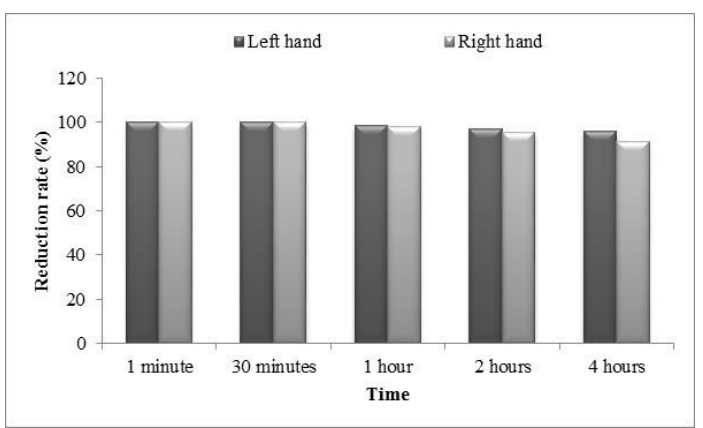

Fig. 8 Antibacterial efficacy of soap based on Ziziphus mucronata bark extract

The results are in agreement with those obtained by Sellah and Mokri [14] who reported reduction rates of $98 \%$ and $91 \%$ with a soap enriched with essential oil, while the unadded soap had reduction rate of $87 \%$ and $33 \%$. The rates of the left hands were different from those of the right hands regardless of the operator. According to the findings, soaps enriched with Ziziphus bark extracts were more effective on bacteria in the left hand than those in the right. This was inconsistence with report of Bennama [15] who obtained reduction rate of $98.60 \%$ and $88.89 \%$ after one minute for the right and left hand, respectively, with soap spiked with lemon (Citrus limon) essential oil. After 2 hours of action, the same author had reduction rate of $80.47 \%$ (right hand) and $20.63 \%$ (left hand). This could be explained by the composition of the plant and how it was used. In the current study, extract was used, whereas previous authors used essential oils.

\section{Conclusion}

The objective of this study was to formulate soaps and ointments enriched with aqueous ethanol extracts from barks of Ziziphus mauritiana and Ziziphus mucronata and assess their antimicrobial activities. The galenic formulation allowed the development of two antimicrobial ointments based on aqueous ethanolic extract of the bark using shea butter as excipient and the formulation of liquid soaps based on a mixture of oils. The studied parameters of the ointments (colour, odour, consistency, stability, $\mathrm{pH}$ and homogeneity) produced satisfactory results. The neutral ointment is yellow in colour while the ointments enriched with extracts are brown in colour. The consistency of the ointments is solid, slightly hard but softens immediately on contact with the skin. As for homogeneity, the method of preparation allowed to obtain a very good homogeneity (regular distribution of the extract). The ointments are stable because there are no changes on the surface of the ointments. With regard to the $\mathrm{pH}$, it is observed that the $\mathrm{pH}$ is acidic. The studied parameters of soaps ( $\mathrm{pH}$ and foaming power) also gave satisfactory results. It is found that the $\mathrm{pH}$ of the soaps is close to neutrality. The enriched soaps foam in saline medium but not in acid medium. According to biological assay, Ziziphus enriched ointments and soaps showed good antimicrobial activity against some fungi and bacteria from skin and hands, respectively.

\section{References}

[1] S. Khrisna, L.S. Miller, Host-pathogen interactions between the skin and Staphylococcus aureus, Curr. Opinion Microbiol.15 (2012) 28-35.

[2] C. Piérard-FranChimont, M. Lesuisse, G.E. Piérard, Deux bactéries et une kyrielle d'infections cutanées communes, Rev. Med. Liège 67 (2012) 513-519.

[3] J. Crabos, Mycoses cutanées à l'officine : étude sur des populations en milieu confiné, Thèse de doctorat, Université de Limoges, Limoges, France, 2013.

[4] WHO, WHO strategy for traditional medicine for 2014-2013, World Health Organization, Geneva, 2013. 
[5] M.E. Abalaka, A. Mann, S.O. Adeyemo, Studies on in-vitro antioxidant and free radical scavenging potential and phytochemical screening of leaves of Ziziphus mauritiana L. and Ziziphus spina-christi L. compared with ascorbic acid, J. Med. Genet. Genomics 3 (2011) 28-34.

[6] O.O. Olajuyigbe, A.J. Afolayan, Phenolic content and antioxidant property of the bark extracts of Ziziphus mucronata Willd. subsp. mucronata Willd, BMC Compl. Alt. Med. 11 (2011) 1-8.

[7] S.Y. Sawadogo, Etudes phytochimiques et activités biologiques des écorces des racines de Zizyphus mauritiana Lam (Rhamnaceae) et des feuilles de Zizyphus mucronata Willd (Rhamnaceae), Thèse de doctorat en Pharmacie, Université de Bamako, Bamako, Mali, 2012.

[8] A.A. Owayss, K. Elbanna, J. Iqbal, H.H. Abulreesh, S.R. Organji, H.S.A. Raweh, A.S. Alqarni, Invitro antimicrobial activities of Saudi honeys originating from Ziziphus spina-christi L. and Acacia gerrardii Benth. trees, Food Sci. Nutr. 8 (2019) 390-401.

[9] Y. Yahia, M.A. Benabderrahim, N. Tlili, M. Bagues, K. Nagaz, Bioactive compounds, antioxidant and antimicrobial activities of extracts from different plant parts of two Ziziphus Mill. species, PLoS one 15 (2020) e0232599.

[10] A. Ashraf, A.S. Raja, A. Farooq, A.S. Shaukat, M.A. Khalid, Chemical composition and biological activities of leaves of Ziziphus mauritiana L. natives to Pakistan, Pak. J. Botany 47 (2015) 367-376.
[11] S. Mohamadou, J. Bayoï, D.R. Djoulde, S.F.S. Nodem, N.L. Tatsadjieu, Phytochemical Screening and Antimicrobial Activity of Ziziphus mauritiana Lam. and Ziziphus mucronata Lam. Extracts, J. Adv. Med. Pharm. Sci. 23 (2021) 25-37.

[12] WHO, World health statistics 2013, World Health Organization, Geneva, 2013.

[13] K. Bene, D. Camara, I.A. Soumahoro, Y. Kanga, G.N. Zirihi, Formulation galénique d'une pommade antimicrobienne à base d'un extrait hydroalcoolique de Bersama abyssinica Fresen, Ethnopharmacologia 58 (2017) 60-69.

[14] L. Sellah, L. Mokri, Préparation d'un savon pâteux et liquide à base d'huiles végétales. Mémoire de master, Université Amira-Béjaïa, Béjaïa, Algérie, 2015.

[15] W. Bennama, Étude de La rémanence d'un savon additionné à l'huile essentielle de citron (Citrus limon), Mémoire de master, Université Abdelhamid Ibn Badis de Mostaganem, Mostaganem, Algérie, 2012.

[16] S. Méité, K.F. Konan, K.N. Guessennd, C. Bahi, A. Djaman, A. Coulibaly, M. Dosso, Antioxidant and antibacterial activity of the extracts of stem bark of Terminalia glaucescens planch ex benth (combretaceae) on enterobacteriaceae extendedspectrum beta-lactamase producing (esbl), Int. J. Pharm. Pharm. Res. 4 (2015) 148-160.

[17] A.B. Yapi, E.D. Théodore, K.K. Fernique, Z.G. Noël, Formulation galénique d'une pommade antimicrobienne à base d'un extrait hydroalcoolique de Aspilia africana (pers.) C.d. Adams var. Africana, une plante de la pharmacopée africaine, Eur. J. Sci. Res. 153 (2019) 207-222 